\title{
Dynamic lumen obstructing angulation in advanced sigmoid-type achalasia success- fully treated by additional proximal curve myotomy
}

Peroral endoscopy myotomy (POEM) is now well accepted as primary treatment for achalasia [1-3]. It is also effective after failed Heller myotomy [4] and can be repeated when symptoms recur [5]. In patients with advanced sigmoid-type achalasia, in addition to failure of relaxation at the lower esophageal sphincter (LES), there may be an additional dynamic obstruction of the distal esophagus due to an acute angulation ( $\mathbf{F i g . 1}$ ). This will redirect the flow of food backwards and inferiorly, which can potentially aggravate the downward bend of the esophagus till it goes below the level of the LES, further worsening food stasis. A real-time dynamic esophagogram is needed to demonstrate this dynamic obstruction. In such cases, myotomy of the LES alone is inadequate, and an additional short myotomy to reduce this acute angulation is needed in order to change flow dynamics and allow free passage of food distally ( $\triangleright$ Fig. $\mathbf{1}$ ).

We report three cases of symptomatic advanced sigmoid-type achalasia with an acute dynamic angulation at the distal esophagus causing lumen obstruction that were treated successfully with an additional curve cutting myotomy during POEM.

The first case was a 60-year-old man with type 1 achalasia who had previously been treated by balloon dilation. The second case was a 53-year-old woman with type 1 achalasia who had previously undergone balloon dilation and two Heller myotomy procedures. The third case was a 73-year-old woman with previous balloon dilation, botox injection, and POEM. Real-time esophagograms demonstrated the obstruction at the LES and at the acute dynamic angulation of the distal esophagus caused by the sigmoidtype morphology. Standard POEM was combined with a short proximal curve myotomy. Post myotomy, the barium esophagogram demonstrated resolution of the obstruction ( $\vee$ Video 1 ).

\section{POEM for sigmoid achalasia: "Curve cutting"}

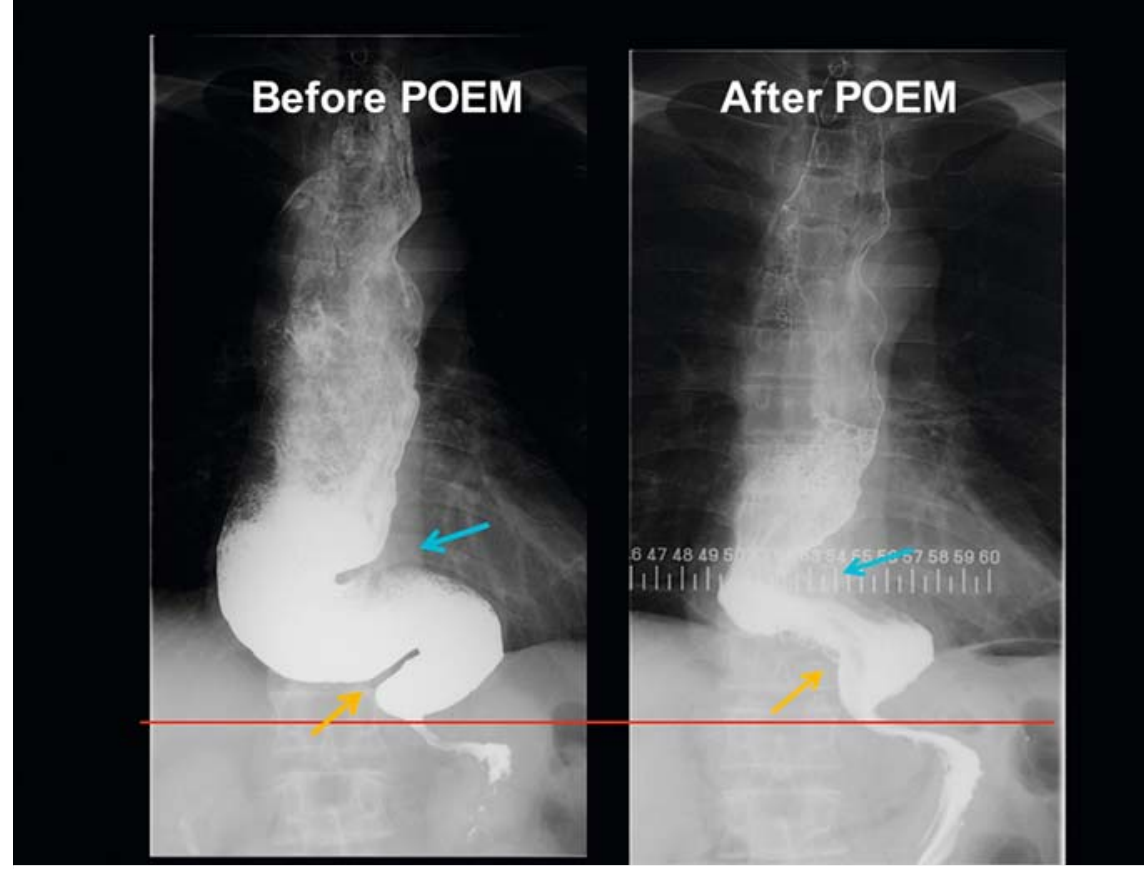

- Fig. 1 Esophagogram before and after peroral endoscopic myotomy (POEM) combined with curve cutting. The red line indicates the level of the lower esophageal sphincter. The blue and yellow arrows indicate the lumen obstructive curves, visible as sharp notches in the barium swallow. After POEM and curve myotomy, the esophagus looks shortened.
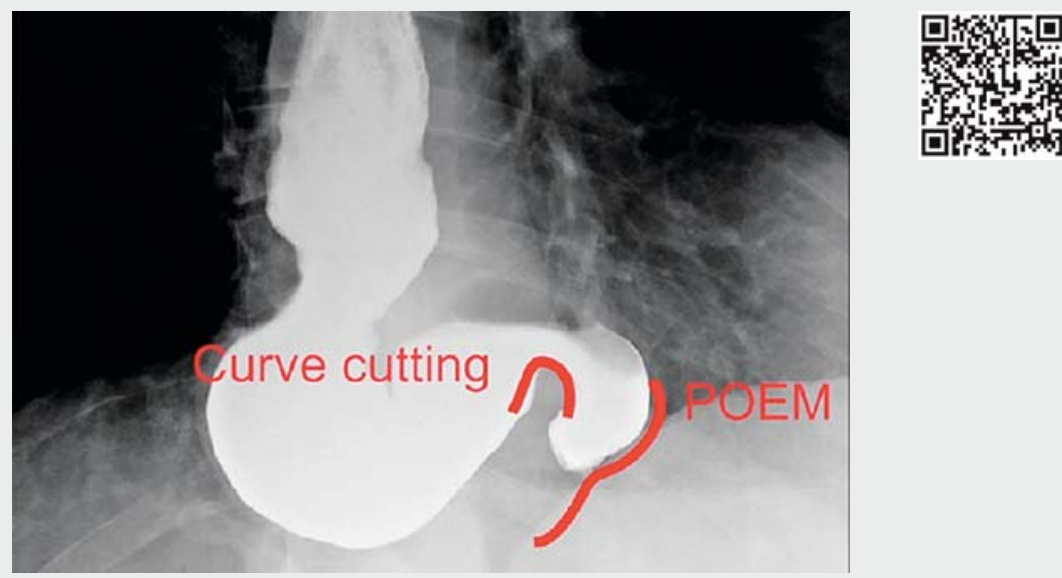

$\checkmark$ Video 1 Dynamic barium esophagogram before and after peroral endoscopic myotomy combined with curve cutting. 
Our report illustrates the importance of careful preprocedural assessment of advanced sigmoid-type achalasia using dynamic real-time esophagogram to ascertain the nature of obstruction, and the value of additional curve cutting myotomy to relieve the dynamic esophageal obstruction.

Endoscopy_UCTN_Code_TTT_1AO_2AJ

\section{Competing interests}

None

The authors

Stefan Seewald ${ }^{1}$, Tiing Leong Ang ${ }^{2}$, Michael Patak $^{3}$, Karl Yu Kim Teng ${ }^{4}$, Haruhiro Inoue ${ }^{5}$

1 Centre of Gastroenterology, Klinik Hirslanden, Zurich, Switzerland

2 Department of Gastroenterology and Hepatology, Changi General Hospital, Singapore

3 Centre of Radiology, Klinik Hirslanden, Zurich, Switzerland

4 Cardinal Santos Medical Center, Metro Manila, Philippines

5 Digestive Disease Centre, Showa University, Koto-Toyosu Hospital, Tokyo, Japan
Corresponding author

\section{Stefan Seewald, MD}

Centre of Gastroenterology, Klinik Hirslanden, Witellikerstrasse 40, 8008

Zurich, Switzerland

Fax: +41-44-3873966

stefan.seewald@gastrozentrum.ch

\section{References}

[1] Inoue H, Minami H, Kobayashi Y et al. Peroral endoscopic myotomy (POEM) for esophageal achalasia. Endoscopy 2010; 42: 265 271

[2] Chiu PW, Inoue H, Rösch T. From POEM to POET: applications and perspectives for submucosal tunnel endoscopy. Endoscopy 2016; 48: $1134-1142$

[3] Ngamruengphong S, Inoue H, Chiu PW et al. Long-term outcomes of per-oral endoscopic myotomy in patients with achalasia with a minimum follow-up of 2 years: an international multicenter study. Gastrointest Endosc 2017; 85: 927 - 933

[4] Ngamruengphong S, Inoue H, Ujiki MB et al. Efficacy and safety of peroral endoscopic myotomy for treatment of achalasia after failed Heller myotomy. Clin Gastroenterol Hepatol 2017; 15: 1531 - 1537

[5] Tyberg A, Seewald S, Sharaiha RZ et al. A multicenter international registry of redo per-oral endoscopic myotomy (POEM) after failed POEM. Gastrointest Endosc 2017; 85 : $1208-1211$

\section{Bibliography}

DOI https://doi.org/10.1055/s-0044-101017

Published online: 16.2.2018

Endoscopy 2018; 50: E117-E118

(c) Georg Thieme Verlag KG

Stuttgart · New York

ISSN 0013-726X

\section{ENDOSCOPY E-VIDEOS}

https://eref.thieme.de/e-videos

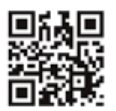

Endoscopy E-Videos is a free access online section, reporting on interesting cases and new

techniques in gastroenterological endoscopy. All papers include a high quality video and all contributions are freely accessible online.

This section has its own submission website at https://mc.manuscriptcentral.com/e-videos 